\title{
OPTIMAL DEBT CONTRACTS IN EMERGING MARKETS WITH MULTIPLE INVESTORS
}

\author{
Karel Janda*
}

\begin{abstract}
:
This paper extends the costly enforcement model of optimal financing to the case of investment projects financed by several lenders when the legal and economic situation in the emerging market economy does not allow for commitment to contracts and for securitization of credit contracts through use of collateral. We consider the asymmetric situation when only one lender is a big strategic investor. All other lenders are small passive investors. We first provide the sufficient and necessary condition for renegotiation proofness. Then we show that the optimal verification is deterministic. We also discuss the conditions under which the optimal contract is a debt contract. Our methodological framework may be used for example for the analysis of credit provision in food supply chains, where often many small non-strategic investors (small farm-level producers) interact with some big strategic investor (the advanced technology supplier) in the explicit or implicit crediting of some parts of food supply chain like the food processing plants or storage facilities.
\end{abstract}

Keywords: Multiple Lenders, Debt, Emerging Markets, Supply Chains.

JEL Classification: C72, D82, G33.

\section{Introduction}

The setting of this paper is the emerging market economy with a very weak legal and economic environment. It is the economy which does not have sufficient internal resources for financing investment projects which may be potentially quite profitable because they fill possible consumption, production or marketing niches appearing during the formation of the emerging market. The financing of such investment projects therefore depends on outside investors. Because our model economy corresponds to the situation in countries undergoing economic transition from post-communist to market economies, we do not consider the investment climate fully dependent on outside resources. These transition countries have some internal resources which may be mobilized for the project financing in addition to the strategic outside investment.

In order to see possible application of our proposed advanced methodology, we may consider the credit dynamics present in food supply chains stretching from farmers to

* Doc. Ing. Karel Janda, M.A., Dr., Ph.D., Transgas-RWE Group Chair in Economics at Department of Microeconomics and Mathematical Methods, Charles University, Opletalova 26, CZ - 11000 Praha 1 and Department of Banking and Insurance, University of Economics, nám. W. Churchilla 4, CZ - 13067 Praha 3 (Karel-Janda@seznam.cz)

The work on this paper was supported by the research project of the Czech Ministry of Education, Youth and Sports, grant number MSM 0021620841 and by the FOODIMA project of the EU's 6FP. 
consumers across the suppliers or technology, manufacturers, retailers and other possible providers or demanders of the credit. The examples of the internal resources in this context are the employees' shares in privatized enterprises, the trade credit provided by the local suppliers in food supply chains, the shares of local farm-level suppliers to the big food manufacturing plants or the credit extended to cooperative organization by its small members in addition to the big outside investor who is acting on different principles than the cooperative members.

One of the defining features of economic transition is the uncertainty connected with changes in law and other legal institutions. We capture this feature of emerging market economy by not relying on commitment to credit contract and instead allowing for contract renegotiations. We also consider a weak legal and enforcement system which does not allow for the full recovery of the scrap value of defaulted projects.

Our model is obviously relevant not only to the emerging markets. It may be used for some credit markets segments in some developed countries too. Characteristic feature for those segments of the credit market is a heterogeneous structure of the investors. Besides a small number of big strategic investors there is a huge number of small investors. These small investors take market conditions as given and do not strategically influence the market. These small investors do not bargain with the borrowers about the conditions of credit contract and leave the monitoring and other interactions with the borrowers to the big strategic investors.

These stylized facts are supported by a recent survey of 542 financially distressed small to medium size non-financial companies conducted by Franks and Sussman (2005). The analysis of this sample shows that the typical debt structure consists of one senior lender (a bank) and a large number of small uncollateralized lenders. The lending contracts for the firms in this sample are usually structured such that the big lender has much stronger bargaining position as compared to small lenders. These small lenders do not act in coordinated way, but they also do not engage in creditor's runs or other forms of coordination failures such as triggering financial distress procedures for the borrower.

While the empirical evidence provided by Franks and Sussman (2005) shows that the small lenders usually do not collude to act as a one big strategic lender, another empirical study by Brunner and Krahnen (2006) provides a different picture with respect to big lenders. In their sample of medium size German companies they find that for the uncollateralized loans the big lenders (banks) usually form bank pools. These are legal institutions aimed at coordinating lender interests when the borrower is in financial distress. This means that the big lenders in the uncollateralized segment of credit market solve the coordination problem of multiple lending by colluding and forming one representative strategic lender.

In our paper we model the stylized credit market corresponding to these conditions. We consider the credit market without any available collateral. On this market we derive the optimal financial contract for financing a firm with multiple investors of a different size and different behaviour. Our methodological framework may be used for example for the analysis of food supply chains, where often many small non-strategic investors (small farm-level producers) interact with some big strategic investor (the advanced technology supplier) in the explicit or implicit crediting of some parts of food supply chain like the food processing plants or storage facilities. The related analysis of the 
credit contracts under asymmetric information in the agricultural and transition economies setting is provided by Janda $(2005,2006 \mathrm{~b})$.

We use the costly state verification framework in which the results of the project are known only by the firm. The investors have to pay verification cost to find out what are these results. As opposed to seminal papers on the costly state verification optimal contracts by Townsend (1979), Diamond (1984), Gale and Hellwig (1985), and Williamson $(1986,1987)$ we do not allow for the commitment to the original contract. In contrast to the papers on credit contracts without commitment by Choe (1998), Khalil and Parigi (1998), and Boyer (2001) we allow for more than two outcomes of the investment process. While we allow for firm's and investor's strategies to be stochastic as in above mentioned papers on credit contracts without commitment, we prove that in our model the optimal contract is deterministic.

In order to characterize an optimal contract we utilize the costly enforcement model of Krasa and Villamil (2000) together with its extensions by Sharma $(2000,2003)$, Krasa and Villamil (2003) and Krasa, Sharma, and Villamil (2004). We extend their results about renegotiable bilateral contracts into the environment with multiple lenders and we show that their major result of optimality of deterministic contract remains true in this environment.

The costly state verification with one active strategic investor and one passive non-strategic investor is studied by Menichini and Simmons (2002) for the investment project with only two possible realizations. Their paper is an extension of Khalil and Parigi (1998).

\section{The Model}

We consider an emerging market economy with a risk neutral firm and a large number of risk neutral investors. These investors are either quite big or very small. We denote the big investors as type $I$ and the small investors as type $T$. The firm owns a technology which requires 1 unit of financing to be provided by the investors. We assume that $\beta$ percent of financing is provided by one big strategic investor and the rest is equally provided by $m$ small non-strategic investors. We assume that this proportion $\beta$ is determined exogenously as a parameter of the model. The introduction of a potentially large number $m$ of small investors serves to capture the stylized fact that quite sizable portion of the total credit may be provided by non-strategic provider(s) without bargaining power during possible renegotiation of the loan contract.

The firm produces a random output $x \in X \equiv\left\{x_{1, \ldots}, x_{n}\right\}$, where $0<x_{1}<\cdots<x_{n}$ The output is privately observed by firm. This private information is the only information asymmetry in the model. All other information is fully shared by all agents in the model. The value of output can by verified by a verification agency at a cost.

The model has 4 time periods. At the period $t=0$ the firm and all investors have a common prior beliefs (probability distribution) $\mu(\cdot)$ over the possible realization in the output space $X$. Firm borrows $\beta$ per cent of needed finance from one strategic investor $I$ and $\frac{(1-\beta)}{m}$ per cent from each small investor. The firm promises to pay all investors $v(x) \geq 0$ per unit of their financial investment at time $t=1$. The firm also specifies that if 
at time $t=3$ the verification agency is called upon to determine the state $x$ the following happens. Each one of the small investors is entitled to $\frac{\eta_{x} x}{m}$. The strategic investor is entitled to an enforceable payment $\eta_{f} F(x, v) \geq 0$. The values of parameters $\eta_{x} \in(0,1)$ and $\eta_{f} \in(0,1)$ serve to capture both the degree to which the absolute priority rule is observed and the division of the legally enforced repayment between small and big investor. (The definition of the absolute priority rule and its relation to our model is provided at the end of this section). For example let's consider the extreme situation when $\eta_{f} \rightarrow 0$ and $\eta_{x} \rightarrow 0$ captures the case in which the absolute priority rule of creditors is extremely violated since the owner of the firm keeps almost all the output and creditors get almost nothing. Another extreme situation, when $\eta_{f} \rightarrow 0$ and $\eta_{x} \rightarrow 1$ describe the case when absolute priority rule is essentially satisfied, since the claims of the creditors have precedence over the claims of the firm's owner, but the legally enforced division of the payments among different classes of the creditors is extremely unequal. In this case the verification agency (the court) is extremely favourable to the small investors who obtain among themselves almost all output while the big investor gets almost nothing. In reality we obviously expect to see less extreme division of output among firm's owner and different classes of creditor.

The theoretical concept of the verification agency may be considered as an abstract substitute for the real life institutions like courts or debt-collection agencies.

At the period $t=1$ the firm privately observes the project realization and decides what the value $v$ will be. All investors immediately obtain their share of this payment $v$. The firm is free to choose different values of $v$ for different realizations of $x$. Since we do not allow for a commitment to the original contract we are not able to use revelation principle which would otherwise imply that the firm truthfully announces the project realization $x$.

At the period $t=2$ the strategic investor may renegotiate the firm's offer with the firm. He may offer that the firm pay him additional money so that his payoff is now $v^{\prime}>v$. If the firm pays this additional money he will not ask for verification agency verification. In the case this offer is accepted, the game ends, otherwise the game proceeds to the next stage. In the case the game ends, the payoffs are as follows. The payoff of strategic investor is $\beta v^{\prime}>\beta v$. The payoff of each of the small investors is $\frac{(1-\beta) v}{m}$. The payoff of the firm is $x-\beta v^{\prime}-(1-\beta) v$.

At the period $t=3$ the strategic investor chooses whether to request verification agency to perform the verification. If no verification is requested, the investors' payoffs remain $\beta v$ and $\frac{(1-\beta) v}{m}$ and the firm's payoff is $x-v$. If the verification is requested, the strategic investor, who asked for verification, pays $\cos t c$ and the verification agency determines the true state $x$. The firm pays $\eta_{f} F(x, v)$ to the strategic investor and $\frac{\eta_{x} x}{m}$ to each of the $m$ small investors. 
We assume that the cost $c$ paid by the investor asking for verification is sufficiently high and the investment share $\frac{1-\beta}{m}$ of any of the small investors is sufficiently low so that it is never optimal for a small investor to initiate the costly state verification proceedings. We also assume that the verification is imperfect in the sense that firm is always able to keep some part of project outcome. Formally we capture this by assuming:

$$
0<\eta_{f}<1,0<\eta_{x}<1, \eta_{f}+\eta_{x}<1,0 \leq F(x, v) \leq x-v-\frac{\eta_{x}}{\eta_{f}} v .
$$

The upper bound on $F(x, v)$ is based on the following consideration. Given that $v$ was paid in the period $t=1$ and there was no renegotiation in the period $t=2, x-v$ remains to be distributed at $t=3$. We capture the imperfect verification by assuming that the firm is able to keep at least $\left(1-\eta_{f}-\eta_{x}\right)(x-v)$. The feasibility condition

$$
x-v \geq \eta_{f} F(x, v)+\eta_{x} x+\left(1-\eta_{f}-\eta_{x}\right)(x-v)
$$

then leads to an upper bound on $F(x, v)$ in (1).

Our assumption of imperfect verification (or alternatively imperfect enforcement) may by also interpreted as a violation of absolute priory rule. This rule is one of the major principles of bankruptcy law. It says that creditors' claims take precedence over shareholders' claims in the event of a liquidation or reorganization. Shareholders are compensated only after creditors have been fully paid off. This principle is documented in both empirical (see Claessens and Klapper, 2005), and theoretical studies (see Knot and Vychodil, 2005). The role of absolute priority rule in the new bankruptcy law in the Czech Republic is covered by Richter (2006).

Nevertheless absolute priority is quite often violated. For publicly traded firms Eberhart and Weiss (1998) and other authors cited by them show that absolute priority was violated in approximately $50-70 \%$ of out-of-court workouts and bankruptcies, depending on the particular sample used. Similarly Berkowitz and White (2004) document widespread absolute priority violation for small firms. Therefore we take absolute priority violation as given in this paper and we investigate its impact on the form of optimal credit contract.

In the following section we will provide the abstract theoretical solution of the credit contracting problem outlined in this section and in the introduction.

\section{The Equilibrium Contract}

The investment problem presented in this model is a dynamic game of incomplete information because payoffs are allowed to change as information changes endogenously during the game. We first define the behavioural strategies of the players. Let the set of all payments $v$ be $V$ and let $\sigma_{F}(v \mid x), v \in V$ denote the firm's mixed strategy at $t=1$. This mixed strategy $\sigma_{F}(v \mid x)$, provides a probability of a choice of each particular payment $v \in V$ after the firm's owner (privately) observes output realization $x \in X$. 
Denote the strategic investor's action of going to the verification agency as $e=1$ and that of not going to the verification agency as $e=0$. Let $\sigma_{I}(e \mid v)$ denote the investor's behavioral strategy at $t=3$. Define the firm's and investors' payoffs at $t=3$ as:

$$
\begin{gathered}
\pi_{F}(x, v, e)=x-v-e\left[\eta_{f} F(x, v)+\eta_{x} x\right] \\
\pi_{I}(x, v, e)=\beta v+e\left[\eta_{f} F(x, v)-c\right] \\
\pi_{i}(x, v, e)=\frac{1-\beta}{m} v+e \frac{\eta_{x} x}{m}, \forall i \in\{1, \ldots, m\},
\end{gathered}
$$

where the $\pi_{F}(x, v, e)$ is the payoff for the owner of the firm, $\pi_{I}(x, v, e)$ is the payoff for the strategic investor and $\pi_{i}(x, v, e)$ is the payoff for each one of the $m$ identical small investors. As a solution concept we use perfect Bayesian Nash equilibrium (PBNE). In this equilibrium of the continuation game, $F(x, v)$ induces $\sigma_{F}$ and $\sigma_{I}$ which are foreseen by all players. That is, in the continuation game starting from $t=1 \sigma_{F}$ maximizes the firm's expected payoff given $\sigma_{I} ; \sigma_{I}$ maximizes the strategic investor's expected payoff given $\mu(\cdot \mid v)$ and $\mu(\cdot \mid v)$ is derived by using Bayes rule whenever possible. Hence we will from now refer to $\left\{F, \sigma_{I}, \sigma_{F}\right\}$ as an equilibrium contract.

We assume that there is a Bertrand competition among possible strategic investors. Therefore in stage $t=0$ we will assume that the strategic investor chooses $\sigma\left\{F, \sigma_{I}, \sigma_{F}\right\}$ to maximize the firm's payoff subject to a set of restrictions. This means that the strategic investor solves

Problem 1. At $t=0$ choose $F, \sigma_{I}, \sigma_{F}$ to maximize

$$
E_{0}\left[u_{F}(x)\right]=\sum_{x \in X} \sum_{v \in V} \sum_{e=0}^{1} \pi_{F}(x, v, e) \sigma_{I}(e \mid v) \sigma_{F}(v \mid x) \mu(x)
$$

subject to

$$
\begin{gathered}
E_{0}\left[u_{I}(x)\right]=\sum_{x \in X} \sum_{v \in V} \sum_{e=0}^{1} \pi_{I}(x, v, e) \sigma_{I}(e \mid v) \sigma_{F}(v \mid x) \mu(x) \geq \bar{u}_{I} \\
E_{0}\left[u_{i}(x)\right]=\sum_{x \in X} \sum_{v \in V} \sum_{e=0}^{1} \pi_{i}(x, v, e) \sigma_{I}(e \mid v) \sigma_{F}(v \mid x) \mu(x) \geq \bar{u}_{I}, \forall i \\
\sigma_{F}, \sigma_{I}, \mu, \mu(\cdot v) \text { is a PBNE at } t=1 \\
v, F, \sigma_{I} \text { is renegotiation proof } \forall x_{i} \in X \text { and } \forall v \mid \sigma_{F}\left(v \mid x_{i}\right)>0 ; \\
0 \leq F(x, v) \leq x-v-\frac{\eta_{x}}{\eta_{f}} v, \forall v \leq x, x \in X .
\end{gathered}
$$


We will characterize and simplify this problem. Let's note first, that since all $m$ small investors are identical and non-strategic, we can represent them by one aggregate non-strategic investor. We assume that the small lenders are not able to collude either because of some legal or institutional reasons or because of too high cost of coordination and collusion. This means that the total aggregated profit, total aggregated expected utilities and total aggregated reservation utilities for all these small lenders may be expressed by one total profit $\pi_{T}(x, v, e)$, total expected utility $E_{0}\left[u_{T}(x)\right]$ and total reservation utility $\bar{u}_{T}$, where the lower index $T$ denotes this total aggregation of small lenders. Therefore instead of (4) we will use

$$
\pi_{T}(x, v, e)=\sum_{i=1}^{m} \pi_{i}(x, v, e)=(1-\beta) v+e \eta_{x} x
$$

and instead of (7) we will use

$$
E_{0}\left[u_{T}(x)\right]=\sum_{x \in X} \sum_{v \in V} \sum_{e=0}^{1} \pi_{T}(x, v, e) \sigma_{I}(e \mid v) \sigma_{F}(v \mid x) \mu(x) \geq \bar{u}_{I}=\sum_{i=1}^{m} \bar{u}_{i} .
$$

We may also note that (10) implies $v \leq \frac{\eta_{f}}{\eta_{f}+\eta_{x}} x$, which implies that $v<x$.

In order to provide the condition for renegotiation proofness we first formally define when the contract is renegotiation proof.

Definition 1. A contract $F$ with associated PBNE strategies $\sigma_{F}, \sigma_{I}$ is renegotiation proof if and only if there does not exist $v$ 'that makes the strategic investor strictly better off and the firm weakly better off in all states, i.e.,

$$
\begin{gathered}
\beta v^{\prime}>\sum_{x \in X} \sum_{e=0}^{1} \pi_{I}(x, v, e) \sigma_{I}(e \mid v) \mu(x \mid v) \\
x-(1-\beta) v-\beta v^{\prime} \geq \sum_{e=0}^{1} \pi_{F}(x, v, e) \sigma_{I}(e \mid v), \forall x \mid \mu(x \mid v)>0 .
\end{gathered}
$$

In case that any contract would be available which would increase the expected payoff for the strategic investor (would make him strictly better off) while not decreasing the expected payoffs for the firm (keeping the firm weakly better off), then the original contract would be renegotiated in favour of this new better contract. Therefore the non-existence of such contract means that the original contract is renegotiation proof. The requirement that the firm is not weakly better off in all states is caused by the fact, that the firm's owner is able to observe the state (the realization of the output) while the investor does not have this information.

Given this definition we provide a sufficient and necessary condition for renegotiation proofness in Lemma 1. The intuition behind Lemma 1 is following. Let's assume that the expected continuation payoff from verification for the strategic investor is smaller than the lowest payment which the firm has to pay both strategic and 
non-strategic investors in case of verification. Then the firm is able to bribe the strategic investor not to ask the verification agency for verification. Condition (15) ensures that this possibility of bribing will not happen.

Lemma 1. For given $V$ and $F$, let $\sigma_{F}$, $\sigma_{I}$ be a PBNE strategies. Then $V, F, \sigma_{I}, \sigma_{F}$ is renegotiation proof for all $v \in V$ with $\sigma_{I}(e=1 \mid v)>0$ if and only if

$$
\sum_{x \in X} \eta_{f} F(x, v) \mu(x \mid v)-c \geq \min _{x \in X, \mu(x \mid v)>0} \eta_{f} F(x, v)+\eta_{x} x .
$$

Proof. We first prove sufficiency. Then we assume that (15) holds. We show that $F, \sigma_{I}, \sigma_{F}$ is renegotiation proof. Let's suppose by contradiction that $F, \sigma_{I}, \sigma_{F}$ is not renegotiation proof. Because we suppose that the contract is not renegotiation proof, there exists $v$ ' which satisfies (14)

$$
\begin{gathered}
x-(1-\beta) v-\beta v^{\prime} \geq x-v-\left[\eta_{f} F(x, v)+\eta_{x} x\right] \sigma_{I}(e=1 \mid v) \\
\beta\left(v^{\prime}-v\right) \leq\left[\eta_{f} F(x, v)+\eta_{x} x\right] \sigma_{I}(e=1 \mid v) \\
\beta\left(v^{\prime}-v\right) \leq \sigma_{I}(e=1 \mid v) \min _{x \in X, \mu(x \mid v)>0}\left[\eta_{f} F(x, v)+\eta_{x} x\right] .
\end{gathered}
$$

Because we suppose that the contract is not renegotiation proof, there also exists $v$, which satisfies (13)

$$
\begin{gathered}
\beta v^{\prime}>\sum_{x \in X}\left[\beta v+\eta_{f} F(x, v)-c\right] \sigma_{I}(e=1 \mid v) \mu(x \mid v) \\
\beta\left(v^{\prime}-v\right)>\sigma_{I}(e=1 \mid v) \sum_{x \in X} \eta_{f} F(x, v) \mu(x \mid v)-c .
\end{gathered}
$$

Inequalities (16) and (17) imply

$$
\sum_{x \in X} \eta_{f} F(x, v) \mu(x \mid v)-c<\min _{x \in X, \mu(x \mid v)>0} \eta_{f} F(x, v)+\eta_{x} x,
$$

which contradicts (15). This completes the sufficiency part of the proof.

Now we prove that (15) is necessary. Let's assume by contradiction that there exist $F$, $\sigma_{I}, \sigma_{F}$, which is renegotiation proof but violates (15) for some $v$. Let

$$
v^{\prime}=v+\sigma_{\mathrm{I}}(1 \mid v)\left[\min _{x \in X, \mu(x \mid v)>0} \eta_{f} F(x, v)+\eta_{x} x\right] .
$$

Because we assume that (15) is violated, the strategic investor's expected payoff, which is given by the $v+\left[\sigma_{I}(1 \mid v)\right.$ times LHS of (15)] is smaller than $v$ 'in (18). Therefore the strategic investor strictly prefers to renegotiate. After substituting (18) into the firm's renegotiation proofness condition (14) we obtain

$$
x-(1-\beta) v-\beta v-\beta \sigma_{I}(1 \mid v)\left[\min _{x \in X, \mu} \eta_{f(x)>0} F(x, v)+\eta_{x} x\right] \geq
$$




$$
\begin{aligned}
& x-v-0[\cdot] \sigma_{I}(0 \mid v)-1\left[\eta_{f} F(x, v)+\eta_{x} x\right] \sigma_{I}(1 \mid v) \\
& \eta_{f} F(x, v)+\eta_{x} x \geq \beta\left[\min _{x \in X, \mu(x \mid v)>0} \eta_{f} F(x, v)+\eta_{x} x\right] .
\end{aligned}
$$

Since $\beta<1$ and $\eta_{x} x>0$, we see that the condition (14) holds even as a strict inequality. This means that the entrepreneur is strictly better off. Therefore $F, \sigma_{I}, \sigma_{F}$ is not renegotiation proof, a contradiction.

Q.E.D.

Lemma 1 implies that verification is deterministic. The term "verification is deterministic" means, that the investor's strategy is either to require verification or not to require verification. That is, the investor never has a mixed (stochastic) strategy, where for a given payment $v$ he would require verification with nontrivial probability strictly between $\mathrm{O}$ and 1 . This is formally expressed in the following Lemma.

Lemma 2. If $F, \sigma_{I}, \sigma_{F}$ solve problem 1 , then $\sigma_{I}(e=1 \mid v) \in\{0,1\}$ for all $v$ such that $\sigma_{F}(v \mid x)>0$ for some $x \in X$.

Proof. Let's assume that $\sigma_{I}(e=1 \mid v)>0$ The right hand side of $(15)$ is strictly positive. Therefore the strategic investor's continuation payoff from verification, which is given by left hand side of (15), is strictly positive. In contrast the continuation payoff from not enforcing is 0 . Therefore, $\sigma_{I}(e=1 \mid v)=1$.

Q.E.D.

Now we show that the optimal contract solving problem 1 has two characteristic features of the debt contract. The first feature is that firm either pays a fixed face value $\bar{v}$ or it does not pay anything and defaults. The second feature is that this default triggers the verification process.

Lemma 3. Let's $\left\{F, \sigma_{I}, \sigma_{F}\right\}$ solve problem 1 . Then there exists $\left\{\widetilde{F}, \widetilde{\sigma}_{I}, \widetilde{\sigma}_{F}\right\}$ which solves problem 1 with the following properties

1. At most the two payments 0 and $\bar{v}$ occur with positive probability, i.e., $\mu(v \mid x)=0$ for all $x \in X, v \notin\{0, \bar{v}\}$.

2. Verification takes places if and only if $v<v^{\prime}$, i.e., $\sigma_{I}(e=1 \mid v)=1 \Leftrightarrow v<\bar{v}$ and $\sigma_{I}(e=1 \mid v)=1 \Leftrightarrow v \geq \bar{v}$.

Proof. First we prove part 2. Consider $\left\{F, \sigma_{I}, \sigma_{F}\right\}$ that solves problem 1 and let $v_{j}$ be some payment which takes place with positive probability from an ex ante perspective and which is followed by no verification, i.e., $\sigma_{F}\left(v_{j} \mid x\right)>0$ for some $x \in X$ and $\sigma_{I}\left(e=1 \mid v_{j}\right)=0$. Optimality of $\sigma_{F}$ then implies that $\sigma_{F}(v \mid x)=0$ for all $v>v_{j}$ irrespective of the value of $\sigma_{I}(e=1 \mid v)$. Hence without any consequence for the payoff of any agent we can set $\sigma_{I}(e=1 \mid v)=0$ for all $v>v_{j}$. If $v_{j}=0$, then the lemma is true. So let $v_{j}>0$ and consider $v<v_{j}$. By Lemma 2, $\sigma(e=1 \mid v) \in\{0,1\}$ If $\sigma_{I}(e=1 \mid v)=0$, then optimality of $\sigma_{F}$ implies that $\sigma_{F}\left(v_{j} \mid x\right)=0$, which is a contradiction. So, $\sigma_{I}(e=1 \mid v)=1$. Defining $\bar{v} \equiv v_{j}$ ends the proof. Thus there is at most one payment $\bar{v}$ such that $\sigma_{F}(\bar{v} \mid x)>0$ and $\sigma_{I}(e=1 \mid \bar{v})=0$. 
Now we prove part 1 . If $\bar{v}=0$ then by part 2 there is no verification for any $v$. This means that firm optimally announces $\bar{v}$ for all $x \in X$. This means that lemma is true for $\bar{v}=0$. So let $\bar{v}>0$. Consider all payments $v<\bar{v}$ and define for each $x_{i}$

$$
\begin{gathered}
\widetilde{F}\left(x_{i}, 0\right)=\frac{v_{k}}{\eta_{f}}+F\left(x_{i}, v_{k}\right) \text { for } v_{k} \text { such that } \sigma_{F}\left(v_{k} \mid x_{i}\right)>0 \\
\widetilde{\sigma}_{F}\left(0 \mid x_{i}\right)=\sum_{v_{k}<\bar{v}} \sigma_{F}\left(v_{k} \mid x_{i}\right) .
\end{gathered}
$$

Because we have shown that statement 2 of this lemma holds and because of Lemma 2, $\widetilde{\sigma}_{I}(e=10)=1$. Equation (20) means that in state $x_{i}$ the firm chooses 0 instead of $v_{k}$, for all $v_{k} \in(0, \bar{v})$ when the $t=3$ payment schedule following a $t=1$ payment of 0 is given by $\widetilde{F}\left(x_{i}, 0\right)$. By choosing 0 instead of $v_{k}$ in state $x_{i}$ the firm gets

$$
x_{i}-0-\eta_{f} \widetilde{F}\left(x_{i}, 0\right)-\eta_{x} x_{i}=x_{i}-v_{k}-\eta_{f} F\left(x_{i}, v_{k}\right)-\eta_{x} x_{i} .
$$

The firm is therefore for all $x \in X$ indifferent between 0 and any payment $v_{k}<\bar{v}$ such that $\sigma_{F}\left(v_{k} \mid x\right)>0$. Because $\sigma_{F}$ is optimal, $\widetilde{\sigma}_{F}$ is also optimal for the firm.

The payoff of strategic investor when the payoff schedule $\widetilde{F}(x, 0)$ is applied is

$$
0+\eta_{f} \widetilde{F}(x, 0)=v_{k}+\eta_{f} F\left(x, v_{k}\right) .
$$

This means that the payoff of the strategic investor is not changed by this transformation.

We need to show feasibility, i.e., $0 \leq \widetilde{F}\left(x_{i}, 0\right) \leq x_{i}$. Clearly $\widetilde{F}\left(x_{i}, 0\right) \geq 0$ by definition. The minimum payoff of the firm in state $x_{i}$ is $\left(1-\eta_{f}-\eta_{x}\right) x_{i}$. Optimality of $\sigma_{F}$ implies that the right hand side of (21), and hence the left hand side of (21) is not less than $\left(1-\eta_{f}-\right.$ $\left.\eta_{x}\right) x_{i}$. That is,

$$
\begin{gathered}
x_{i}-0-\eta_{f} \widetilde{F}\left(x_{i}, 0\right)-\eta_{x} x_{i} \geq\left(1-\eta_{f}-\eta_{x}\right) x_{i} \\
\widetilde{F}\left(x_{i}, 0\right) \leq x_{i} .
\end{gathered}
$$

We next show that $\left\{\widetilde{F}, \widetilde{\sigma}_{I}, \widetilde{\sigma}_{F}\right\}$ is renegotiation proof. Let $\widetilde{\mu}\left(x_{i} \mid 0\right)$ be the strategic investor's updated prior given $\widetilde{\sigma}_{F}$. The definition of $\widetilde{\sigma}_{F}$ in (20) implies that $\widetilde{\mu}\left(x_{i} \mid 0\right)>0$ if and only if $\mu\left(x_{i} \mid v_{j}\right)>0$ for some $v_{j}<\bar{v}$. This and (21) imply

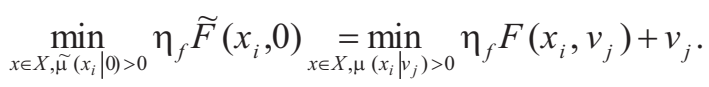

Contract $\left\{F, \sigma_{I}, \sigma_{F}\right\}$ is renegotiation proof. Therefore,

$$
\sum_{x \in X} \eta_{f} \widetilde{F}(x, 0) \widetilde{\sigma}_{F}(0 \mid x) \mu(x)
$$




$$
\begin{gathered}
=\sum_{x \in X} \sum_{v_{j}<\bar{v}} \eta_{f} \widetilde{F}(x, 0) \sigma_{F}\left(v_{j} \mid x\right) \mu(x) \\
=\sum_{x \in X} \sum_{v_{j}<\bar{v}}\left[\eta_{f} F\left(x, v_{j}\right)+v_{j}\right] \sigma_{F}\left(v_{j} \mid x\right) \mu(x) \\
=\sum_{v_{j}<\bar{v}} \sum_{x \in X}\left[\eta_{f} F\left(x, v_{j}\right)+v_{j}\right] \mu\left(x \mid v_{j}\right) \sum_{x \in X} \sigma_{F}\left(v_{j} \mid x\right) \mu(x) \\
\geq \sum_{v_{j}<\bar{v}}\left[\min _{x \in X, \mu} \eta_{\left(x \mid v_{j}\right)>0} F\left(x, v_{j}\right)+\eta_{x} x+v_{j}+c\right] \sum_{x \in X} \sigma_{F}\left(v_{j} \mid x\right) \mu(x) \\
=\sum_{v_{j}<\bar{v}}\left[\min _{x \in X, \tilde{\mu}(x \mid 0)>0} \eta_{f} \widetilde{F}(x, 0)+\eta_{x} x+c\right] \sum_{x \in X} \sigma_{F}\left(v_{j} \mid x\right) \mu(x) \\
=\left[\min _{x \in X, \widetilde{\mu}(x \mid 0)>0} \eta_{f} \widetilde{F}(x, 0)+\eta_{x} x+c\right] \sum_{x \in X} \widetilde{\sigma}_{F}(0 \mid x) \mu(x)
\end{gathered}
$$

The equalities (26) and (31) follow from (20). The equality (27) follows from (19). The equality (28) is given by Bayesian updating. The inequality (29) follows from (15). The equality (30) follows from (24). Dividing (25) and (31) by $\sum_{x \in X} \widetilde{\sigma}_{F}(0 \mid x) \mu(x)$ yields

$$
\sum_{x \in X} \eta_{f} \widetilde{F}(x, 0) \widetilde{\mu}_{F}(x \mid 0)-c \geq \min _{x \in X, \bar{\mu}(x \mid 0)>0} \eta_{f} \widetilde{F}(x, 0)+\eta_{x} x .
$$

Because of Lemma 1, the contract $\left\{\widetilde{F}, \widetilde{\sigma}_{I}, \widetilde{\sigma}_{F}\right\}$ is renegotiation proof. Also $\widetilde{\sigma}_{I}(e=10)=1$ is optimal because the right hand side of (32) is strictly positive. Q.E.D.

As a consequence of Lemma 3 it is sufficient to consider strategies $\sigma_{F}$ for which at most two payments occur in equilibrium. If payment $\bar{v}$ is made, then no verification occurs. We can therefore assume that $F(x, \bar{v})=0$. As a consequence, only payments $F(\cdot, 0)$ occur in equilibrium. Define $f(x)=F(x, 0)$. Let $\sigma_{d}(x)=\sigma_{F}(0 \mid x)$ be the probability that the firm does not pay, i.e., $\sigma_{d}(x)$ is the bankruptcy probability. Let $\mu(x \mid d)=$ $=\mu(x \mid v=0)$.

Then we can rewrite problem 1 as

Problem 2. At $t=0$ choose $\left\{\bar{v}, f, \sigma_{d}\right\}$ to maximize

$$
E_{0}\left[u_{F}(x)\right]=\sum_{x \in X}\left[x-\left(\eta_{f} f(x)+\eta_{x} x\right) \sigma_{d}(x)-\bar{v}\left(1-\sigma_{d}(x)\right)\right] \mu(x)
$$

subject to

$$
E_{0}\left[u_{I}(x)\right]=\sum_{x \in X}\left[\left(\eta_{f} f(x)-c\right) \sigma_{d}(x)+\beta \bar{v}\left(1-\sigma_{d}(x)\right)\right] \mu(x) \geq \bar{u}_{I}
$$




$$
\begin{gathered}
E_{0}\left[u_{T}(x)\right]=\sum_{x \in X}\left[\eta_{x} x \sigma_{d}(x)+(1-\beta) \bar{v}\left(1-\sigma_{d}(x)\right)\right] \mu(x) \geq \bar{u}_{T} \\
\sigma_{d}(x)=\left\{\begin{array}{cl}
1 & \text { if } \bar{v}>\eta_{f} f(x)+\eta_{x} x \\
0 & \text { if } \bar{v}>\eta_{f} f(x)+\eta_{x} x \\
\alpha \in[0,1] & \text { if } \bar{v}>\eta_{f} f(x)+\eta_{x} x
\end{array}\right.
\end{gathered}
$$

If $\sigma_{d}(x)>0$ for an $x \in X$ (i.e., bankruptcy occurs) then:

$$
\begin{gathered}
\sum_{x \in X} \eta_{f} f(x) \mu(x \mid d)-c \geq \min _{x \in X, \mu(x \mid d)>0} \eta_{f} f(x)+\eta_{x} x \\
\bar{v} \leq\left(\eta_{f}+\eta_{x}\right) x_{n}-c \\
0 \leq f(x) \leq x, \forall x \in X \\
\bar{v} \leq \frac{\eta_{f}}{\eta_{f}+\eta_{x}} x, \forall x \in X \text { such that } \sigma_{d}(x)=0
\end{gathered}
$$

If we solve problem 2 and effectively ignore payments $v \in(0, \bar{v})$, then we must make sure that $f$ can be extended to a payment schedule $F(x, v)$ for all $v \in(0, \bar{v})$. The following Lemma 4 proves that the inequality (40) is the appropriate necessary and sufficient condition for contract $\left\{F, \sigma_{I}, \sigma_{F}\right\}$ to solve problem 1 .

Lemma 4. Let's consider $\left\{\bar{v}, f, \sigma_{d}\right\}$ that solves problem 2 . Then there exists $\left\{F, \sigma_{I}, \sigma_{F}\right\}$ that solves problem 1 with $F(x, 0)=f(x), \sigma_{F}(0 \mid x)=\sigma_{d}(x), \sigma_{F}(\bar{v} \mid x)=1-\sigma_{d}(x)$ if and only if condition (40) is satisfied.

Proof. (i) Let's suppose that (40) is violated. Then there exists $\varepsilon>0$ such that $\bar{v}-\varepsilon>\left(\eta_{f}+\eta_{x}\right) x_{n}-c$. Therefore, if $\bar{v}-\varepsilon$ is paid then it is optimal for the investor to choose $e=0$. But then it cannot be optimal for the firm to pay $\bar{v}$ in any state.

(ii) Let the strategic investor's beliefs be such that $\mu\left(x_{n} \mid v\right)=1$ for all $0<v<\bar{v}$. Hence $e=1$ is strictly optimal for all such $0<v<\bar{v}$ as $v<\left(\eta_{f}+\eta_{x}\right) x_{n}-c$. As $F\left(x_{i}, 0\right) \leq x_{i}$ for all $x_{i}$, the firm cannot be strictly better off by choosing $v$ other than 0 or $\bar{v}$. Q.E.D.

In the following proposition we show that the solution of the problem 2 is a debt contract under which the firm pays maximum enforceable payment to strategic lender in the case of default.

Proposition 1. As long as renegotiation proofness condition (39) is satisfied as a strict inequality, the optimal payment schedule solving problem 2 is $f(x)=x$.

Proof. Strategic investor's participation constraint (34) binds in equilibrium. Let's suppose by contradiction that (34) does not bind. Then there exists $\varepsilon>0$ and $x^{\prime} \in X$ with $\sigma_{d}\left(x^{\prime}\right)>0$ such that (34) is still satisfied for $f^{\prime}\left(x^{\prime}\right)=f\left(x^{\prime}\right)-\varepsilon$ without violating conditions 
(35) - (42). Firm's payoff (33) is higher for $f^{\prime}\left(x^{\prime}\right)$ than for $f\left(x^{\prime}\right)$ which leads to contradiction.

Case 1. Non-strategic investor's participation constraint (35) binds.

By adding (34) and (35) we obtain

$$
\sum_{x \in X}\left[\left(\eta_{f} f(x)+\eta_{x} x\right) \sigma_{d}(x)+\bar{v}\left(1-\sigma_{d}(x)\right)\right] \mu(x)=\bar{u}_{I}+\bar{u}_{T}+\sum_{x \in X} c \sigma_{d}(x) \mu(x) .
$$
obtain

After substituting for $\sum_{x \in X}\left[\left(\eta_{f} f(x)+\eta_{x} x\right) \sigma_{d}(x)+\bar{v}\left(1-\sigma_{d}(x)\right)\right] \mu(x)$ in (33) we

$$
E_{0}\left[u_{F}(x)\right]=\sum_{x \in X} x \mu(x)-\left(\bar{u}_{I}+\bar{u}_{T}\right)-\sum_{x \in X} c \sigma_{d}(x) \mu(x) .
$$

Minimization of $\sum_{x \in X} c \sigma_{d}(x) \mu(x)$ then requires $f(x)=x$.

Case 2. Non-strategic investor's participation constraint (35) does not bind.

From binding (34) we obtain

$$
\bar{v} \sum_{x \in X}\left[1-\sigma_{d}(x)\right] \mu(x)=\frac{\bar{u}_{I}-\sum_{x \in X}\left[\eta_{f} f(x)-c\right] \sigma_{d}(x) \mu(x)}{\beta}
$$

After substituting (43) in (33) we get

$$
E_{0}\left[u_{F}(x)\right]=\sum_{x \in X} x \mu(x)-\frac{\bar{u}_{I}}{\beta}+\frac{\sum_{x \in X}\left[(1-\beta) \eta_{f} f(x)-\beta \eta_{x} x-c\right] \sigma_{d}(x) \mu(x)}{\beta}
$$

Since right-hand-side of (44) is increasing in $f(x)$, setting $f(x)=x$ maximizes $E_{0}\left[u_{F}(x)\right]$.

Q.E.D.

\section{Conclusion}

In our paper we deal with the problem of investment financing by multiple investors in the credit market on which no collateral is available to secure the loan. The model conditions of the credit market without a good collateral available and without ability to commit to the signed contract is quite relevant for the emerging markets. Especially in the times like the start of economic transition in the post-communist countries, we often encounter the situation when the strategic investor realizes that a good business opportunity is available and finances the promising project without a security provided by sufficient collateral. Such strategic investor often provides only part of the capital needed while the rest is provided by small passive investors like workers or privatization voucher holders in voucher privatization scheme. In the situation of quick economic transition the owner of the project (the borrower) is often not able to provide 
sufficient collateral to secure the return of the loan to the lender in the case of the project's failure. The borrowers usually do not have sufficient outside funds to use as the collateral and the project assets (like the old privatized machinery or buildings) may be almost worthless in the case of project failure.

In addition to the already mentioned problems, the legal culture, enforcement technologies and expected changes in the law codes during the transition do not allow for credible commitment to the written contracts and create the space for possible renegotiations. In accord with the stylized facts of emerging markets we also assume that the legal and economic enforcements procedures are so weak that the defaulting entrepreneur is able to hide part of the value of the project and prevent the transfer of this hidden part to the lender in the case of bankruptcy procedures.

Following Menichini and Simmons (2002) we consider a case with one big strategic investor and a number of small non-strategic investors. Since we do not allow for the commitment to original contract we are not able to use standard revelation principle argument as introduced by Townsend (1979). Instead we use the Perfect Bayesian Equilibrium concept as used in related papers by Krasa and Villamil (2000) and Bester and Strausz (2001).

Since Townsend (1979) it is known that when the commitment to the original contract is possible then in the costly state verification model the contracts with stochastic verification dominate the contracts with deterministic verification. This result continues to hold in the costly state verification models with impossibility of commitment, as shown by Choe (1998) and Khalil and Parigi (1998) in the models with one investor and only two possible outcomes of investment projects. Menichini and Simmons (2002) show that the optimality of stochastic verification survives an introduction of multiple investors into the costly state verification model with two possible outcomes and with impossibility of commitment. In our model we show that allowing for more than two possible outcomes and using costly state verification as introduced by Krasa and Villamil (2000) leads to different results. The optimal contract in our model is a renegotiation proof deterministic debt contract.

\section{References}

Berkowitz, J., White, M. J. (2004), "Bankruptcy and Small Firms' Access to Credit." RAND Journal of Economics, 35(1), pp. 69-84, spring 2004.

Bester, H., Strausz, R. (2001), "Contracting with Imperfect Commitment and the Revelation Principle: The Single Agent Case." Econometrica, 69(4), pp. 1077-1098, July 2001.

Boyer, M. (2001), "Project Financing when Principal Cannot Commit." University of Montreal, Mimeo, March 2001.

Brunner, A., Krahnen, J.P. (2006), "Multiple Lenders and Corporate Distress: Evidence on Debt Restructuring." Working Paper CFS 2001/04, Center for Financial Studies, June 2006.

Chongwoo Choe (1998), "Contract Design and Costly Verification Games." Journal of Economic Behavior and Organization, 34(2), pp. 327-340, February 1998.

Claessens, S., Klapper, L.F. (2005), "Bankruptcy around the World: Explanations of its Relative Use." American Law and Economics Review, 7(1), pp. 253-283, spring 2005.

Diamond, D. W. (1984), "Financial Intermediation and Delegated Monitoring." Review of Economic Studies, 51(3), pp. 393-414, July 1984.

Eberhart, A.C., Weiss, L.A. (1998), "The Importance of Deviations from the Absolute Priority Rule in Chapter 11 Bankruptcy Proceedings." Financial Management, 27(4), pp. 106-110, winter 1998. 
Franks, J., Sussman, O. (2005), "Financial Distress and Bank Restructuring of Small to Medium Size UK Companies." Review of Finance, 9(1), pp. 65-96, 2005.

Gale, D., Hellwig, M. (1985), "Incentive-Compatible Debt Contracts: The One-Period Problem." Review of Economic Studies, 52(4), pp. 647-663, October 1985.

Janda, K. (2005), "The Comparison of Credit Subsidies and Guarantees in Transition and Post-Transition Economies." Ekonomický časopis/Journal of Economics, 53(4), pp. 383-398, 2005.

Janda, K. (2006), "Analysis of the Budgetary Costs of the Supporting and Guarantee Agricultural and Forestry Fund." Czech Journal of Economics and Finance, 56(9-10), pp. 416-434, 2006.

Khalil, F., Parigi, B. (1998), "The Loan Size as a Commitment Device." International Economic Review, 39(1), pp. 135-150, February 1998.

Knot, O., Vychodil, O. (2005), "What Drives the Optimal Bankruptcy Law Design." Czech Journal of Economics and Finance, 55(3-4), pp. 110-123, 2005.

Krasa, S., Sharma, T., Villamil, A.P. (2004), "Bankruptcy and Firm Finance." Mimeo, September 2004.

Krasa, S., Villamil, A.P. (2000), "Optimal Contracts when Enforcement Is a Decision Variable." Econometrica, 68(1), pp. 119-134, January 2000.

Krasa, S., Villamil, A.P. (2003), "Optimal Contracts when Enforcement is a Decision Variable: A Reply." Econometrica, 71(1), pp. 634-635, January 2003.

Menichini, A. M., Simmons, P. (2002), "Are Two Investors Better than One?" Paper presented at EEA/ESEM meetings, August 2002.

Richter, T. (2006), "The New Czech Insolvency Act - New Insolvency Regime for Czech Corporate Debtors and Their Credit." Butterworths Journal of International Banking and Financial Law, 21(6), pp. 271-272, June 2006.

Sharma Tridib (2000), "Optimal Renegotiation Proof Debt Contracts." Working Paper, CIE, ITAM.

Sharma Tridib (2003), "Optimal Contracts when Enforcement Is a Decision Variable: A Comment." Econometrica, Forthcoming 2003.

Townsend, R.M. (1979), "Optimal Contracts and Competitive Markets with Costly State Verification." Journal of Economic Theory, 21(2), pp. 265-293, October 1979.

Williamson, S.D. (1986), "Costly Monitoring, Financial Intermediation, and Equilibrium Credit Rationing." Journal of Monetary Economics, 18, pp. 159-179, September 1986.

Williamson, S.D. (1987), "Costly Monitoring, Loan Contracts and Equilibrium Credit Rationing." Quarterly Journal of Economics, 102, pp. 135-146, February 1987. 